\title{
De la producción periodística a la investigación de campo. El ciclo televisivo "Cárceles, un mundo adentro"
}

From journalistic production to field research. The television series "Cárceles, un mundo adentro"

\author{
Lucila Calderone lucilacalderone@hotmail.com \\ https://orcid.org/0000-0002-1417-1391 \\ Universidad Nacional de San Martín (Argentina)
}




\section{Resumen}

A partir de mi trabajo como productora de televisión ingresé en 2008 en el ámbito carcelario. Cómo antropóloga y como productora tuve que problematizar mi presencia en el campo, resolver mis propios tabues y pre conceptos para poder cumplir los objetivos de mi investigación. En el trayecto, descubrí que lo primero que debía hacer era deconstruir el proceso de acceso al campo como productora/investigadora.

Palabras clave: Cárceles; televisión; antropología.

\section{Abstract}

From my work as a television producer, I entered the prison in 2008. As an anthropologist and as a producer, I had to problematize my presence in the field, solve my own taboos and previous concepts in order to fulfill the objectives of my research. Along the way, I discovered that the first thing I should do was deconstruct the process of access to the field as a producer / researcher.

Keywords: Prisions; television; anthropology.

En 2008 comencé a trabajar en la producción del programa de televisión "Cárceles, un mundo adentro". El mismo se emitía por Telefé y era conducido por el actor Diego Alonso. El ciclo había comenzado unos años atrás, pero se había interrumpido luego de siete capítulos. En 2008, el canal decidió volver a emitirlo y se comenzó una nueva temporada. Para ese entonces yo trabajaba ya en Endemol Argentina (ahora conocida como Kuarzo), la productora de televisión de Martín Kweller, que había armado este programa. Cuando el canal anuncia la vuelta de este formato, me designan a mí como coordinadora de producción y productora del 
mismo. La coordinación de producción consiste en organizar logísticamente el programa (movilidad, camarógrafos, productores, caja chica) y a su vez coordinar con el Ministerio de Justicia de la provincia de Buenos Aires y con los juzgados los accesos a los penales y las autorizaciones judiciales para grabar a los detenidos.

Antes de comenzar el proyecto, el director artístico de Endemol (en ese entonces), Eloy Alazard, el productor ejecutivo del programa, Gustavo Hazan y yo como coordinadora, nos reunimos con el ministro, el Sr. Rosales (1) y su secretario Alfonso Banco, antes para reprogramar el acceso a los penales que ya había sido tramitado previamente, en la edición anterior del programa. La reunión fue en La Plata, en la oficina del ministro, y en ella se pautó como sería el ingreso a las cárceles bonaerenses y cómo llevaríamos adelante el tramiterío legal para obtener las autorizaciones de cada juzgado para que no se emita en el programa ninguna nota de algún detenido que no haya sido autorizado por su juzgado a salir en cámara. A su vez, pactamos de palabra la buena predisposición del Ministerio con el programa y la intención de visibilizar las cárceles, aceptando las consecuencias que esto pudiera traer. En este tipo de reuniones, siempre se cuidaban las formas y de ninguna manera nos decían que algo no se podía mostrar. Muy por el contrario, se hablaba de que el programa era útil para ellos, para mostrar lo que se hacía.

Una vez obtenido el permiso y el visto bueno del Ministro, mi contacto directo era Gerardo Bermúdez, jefe de prensa del Servicio Penitenciario Bonaerense (de ahora en más SPB). La rutina para que un equipo de producción pudiera ingresar a un penal era la siguiente, yo tenía que mandarle un mail a Gustavo diciéndole qué día quería ingresar a determinado penal y él chequeaba si no había ningún inconveniente. En este mail o fax debía aclarar nombre y DNI de las personas que quisieran ingresar, penal seleccionado, día y horario. Esto generalmente se tramitaba de un día para otro. Supuestamente teníamos acceso a cualquier unidad sin inconvenientes, sin embargo, los directores de algunas unidades penitenciarias a veces presentaban objeciones o nos pedían que cambiáramos de día y lo podíamos conversar. Nosotros procurábamos no generar inconvenientes e ir cuando estaban todos de acuerdo. Aunque a veces algunos penales tenían reiterativas excusas para que no fuéramos, por ejemplo, "hoy no que es día de visita y los internos están revolucionados"; "hoy mejor no que estamos preparando un evento y no los podemos recibir". Lo ideal era programarlo con la mayor anticipación posible. Cuando yo obtenía el ok del jefe de prensa, programábamos una visita que nosotros llamábamos previa. La previa consistía en ir a un penal a conocer a los detenidos que alojaba y sus historias de vida. En estas ocasiones los productores íbamos solos o de a dos, sin cámaras e ingresábamos a los pabellones en busca de algo que contar o 
mostrar. A veces eran buenas historias, otras el simple encuentro con situaciones, dinámicas o espacios desconocidos nos permitía mostrar aquello que para los que trabajan ahí era su espacio cotidiano, pero para muchos que no estábamos relacionados con el interior de las cárceles nos resultaba sorprendente y desconocido, aterrados e intrigante a la vez.

En el marco del programa de televisión, nosotros los productores, respondíamos a ciertos parámetros pre establecidos sobre qué consistía una buena historia. Para que un caso fuese televisable tenía que presentar distintos factores. Para empezar, la detenida/o tenía que poder hablar frente a cámara sin inhibirse, con claridad y en un volumen relativamente alto. Si bien el aspecto físico no era condicional, el mismo ayudaba o no a la hora de elegir el caso (2). A su vez, su historia de vida debía tener altibajos propios de una novela o esto podía ser reemplazado con la elocuencia del detenido y su forma de narrar su vida. Estos puntos eran fundamentales a la hora de establecer una grabación que respondía a los intereses de un programa de televisión que se emitía por un canal de aire que buscaba aumentar el raiting sumando televidentes y partiendo de la idea, muchas veces subjetiva de qué es lo que la gente quiere ver y qué no.

A veces íbamos con una idea previa, buscando tratar un tema específico como madres, evangelistas, moda, calor. $\mathrm{Y}$ a veces simplemente a ver con qué nos encontrábamos para a partir de lo que percibíamos, pensar una nota para grabar. El acceso era muy directo. Salvo que hubiese habido un incidente imprevisto, nosotros llegábamos a la unidad, nos anunciábamos en la recepción, presentábamos nuestras credenciales de prensa, nos tomaban los datos e ingresábamos al penal. Una vez adentro elegíamos el pabellón que queríamos visitar y sin ser requisados ingresábamos. Bastaba con que nos anunciaramos con nuestra credencial de prensa (impresa por nosotros mismos), para que nos abrieran las puertas y las rejas de acceso al pabellón que habíamos elegido. La elección cuando íbamos a una cárcel por primera vez era al azar. Otras veces, pedíamos ir a un sector dónde ya conocíamos a algún detenido que nos recibiera y nos ayudara en la búsqueda. A veces porque querían colaborar y nos decían "tienen que conocer a...", otras, simplemente su buen recibimiento nos facilitaba el acceso a conversar con los nuevos integrantes del pabellón.

Los guardias nos abrían la reja, nos dejaban pasar al interior y volvían a cerrar la reja. Nosotros quedábamos al interior del pabellón, y los guardias afuera.

A partir de estas previas los productores elegíamos a los detenidos que nos interesaba volver a grabar. Una vez hecha esta selección debíamos solicitarles nombre completo, DNI, número de causa y juzgado de la misma. Cuando volvíamos de la previa elaborábamos con estos datos 
una solicitud judicial que debíamos enviar al juzgado correspondiente por fax y este generalmente se tomaba entre una semana y 15 días para expedir una resolución. Generalmente los internos eran autorizados a dar notas. Sin embargo, cuando un juzgado consideraba que no era pertinente grabar a un interno no podíamos hacer nada al respecto. Este trabajo de enviar las solicitudes lo realizaba una asistente de producción y una vez obtenido el permiso lo enviábamos a prensa del SPB para que entonces ellos nos habiliten el acceso con cámara al penal en cuestión.

Para permitirnos o no la grabación de un detenido los juzgados se amparaban generalmente en dos discursos. Aquellos que lo autorizaban se basaban en la libertad de expresión de las personas que aunque estuviesen privadas de su libertad tienen que tener la posibilidad de elegir por sí mismas si desean hablar con un medio de comunicación o no. Los juzgados que nos daban la negativa, se basaban en que ellos eran responsables de mantener la integridad de las personas detenidas a su cargo y que no consideraban que el programa fuese beneficioso para tales fines. El Ministerio avalaba el programa y nos ayudaba en algunos casos donde los directivos del penal estaban reacios a dejarnos ingresar, pero con el tema de autorizaciones judiciales nada podían hacer. En los años que hicimos este programa nunca pudimos revertir la decisión de un juzgado.

En el programa había distintos tipos de notas. Podría clasificarlas en distintos tipos: informes, mano a mano, entrevistas plantadas y reallity.

Los informes trataban un tema desde distintos puntos de vista, opiniones y detenidos. Se elegía un tema específico y se armaba una nota que diera cuenta de todas las variantes del mismo. Generalmente los informes incluían entrevistas plantadas, que eran las entrevistas que realizábamos los productores a uno a varios presos, y reallity que consistía en grabar acciones (no actuadas) de la vida cotidiana que tuvieran que ver con el tema tratado. El mano a mano era la entrevista realizada por el conductor a un detenido y generalmente trataba sobre la historia personal y delictiva de un sujeto en particular y también era complementada por una entrevista previa grabada con el productor.

Este programa se mantuvo al aire hasta 2010 con una emisión semanal. Nuestro trabajo diario consistía en como describí anteriormente visitar los penales todas las semanas y seguir la condena de algunos de los presos que tomaron protagonismo en el ciclo.

Una vez que el programa terminó su temporada, me alejé completamente del campo. 
En las ocasiones que se nos negaba el acceso reiteradamente teníamos que ponernos en contacto con el Ministerio para que nos facilitara el acceso o hablara con el director de la unidad en cuestión para ver qué es lo que estaba ocurriendo. Muchas veces llegamos a la conclusión que les molestaba nuestra presencia de por sí. Cuando ingresabas a una unidad con una cámara de televisión la sensación era la de una inspección, quizás mucho más complicado que una inspección porque lo que registrase la cámara implicaba exposición pública. En este caso, no solo podía traerles problemas con sus superiores si veían en el programa algo que no estaba en orden, sino que además la repercusión era pública. El programa lo veían los presos, los guardias cárceles, los directivos, sus familiares, vecinos y miles de televidentes más. Las veces que el programa evidenció algo que no estaba funcionando correctamente, y acá quiero hacer una aclaración, la repercusión fue a gran escala. Directores de penales trasladados, sancionados, reprendidos y además expuestos. Lo que quisiera aclarar es la dicotomía en la que se encontraba el programa a la hora de ser juzgado, debatiéndose entre un programa de denuncia y un show de entretenimiento. El programa se creó buscando abrir una ventana a un mundo invisibilizado, pero claramente se emitía por un canal de aire el cual tenía intereses económicos sobre el mismo, como mantenerse al aire, hacer raiting para poder vender publicidad. A su vez, era realizado por jóvenes que buscaban decir algo y tenían sus propios objetivos personales. Algunos buscábamos conocer más sobre un campo desconocido, otros por curiosidad periodística, otros generar un espacio de recreación y algunos lo tomaban solo como parte de su trabajo. En verdad, creo que para todos significaba un poco de todo eso. Si bien no era un programa de denuncia no se ocultaban las cosas que veíamos o por lo menos eso intentábamos. Sin embargo, existía una presión tacita por parte del ministerio que establecía que no los denunciemos en exceso o tan explícitamente porque entonces nos quitaban el permiso. Esto muy pocas veces fue dicho literalmente. Alguna vez presencie en esa misma reunión un comentario por parte de Alfonso Banco en referencia a estos temas:

\footnotetext{
Ustedes tienen la libertad de mostrar lo que pasa, si algo está mal es nuestro error y debemos resolverlo, pero les pedimos por favor que no aborden esta temporada el tema de la comida porque estamos luchando para mejorarlo y que salga en Telefé solo trabaría las cosas y no podríamos avanzar (comunicación personal, Alfonso Blanco).
} 
Es decir, de manera sutil y no tanto nos decían no se metan con esto. Sin embargo, a lo largo de los más de 100 episodios que emitió el programa, se trataron temas sumamente conflictivos. Algunas veces las consecuencias fueron grandes, no solo para los responsables que se veían sancionados, sino para nosotros que recibíamos alguna llamada del tipo "me tendrías que haber avisado que ibas a emitir eso" y luego un tiempo de "penitencia" en el cual no nos habilitaban todas las unidades, demoraban nuestro acceso cuando concurríamos a los penales, tardaban en darnos los permisos y a veces nos imponían nuevas normas del tipo "llamar al jefe de prensa antes de cada emisión y contarle lo que iba a ocurrir en ese programa". Estas medidas en el tiempo se diluían y volvíamos a la cotidianeidad. Muchas veces, los productores ejecutivos que tuvo el programa conociendo esta situación decidían emitir una nota igual y afrontar estas conocidas consecuencias o a veces aprovechar el descuido de los directivos que se olvidaban del programa, no lo miraban y quizás así fue como salieron al aire muchas cosas que claramente mostraban el pésimo funcionamiento de algunas cuestiones y nada pasaba y seguíamos grabando. Un ejemplo de esto fue cuando se emitió una nota donde los detenidos mostraban como preparaban "pajarito" una bebida alcohólica preparada a base de fermentación que claramente se encuentra prohibida. Los reclamos por esa emisión llegaron mucho después con una repetición del programa ya emitido tiempo atrás.

Cuando digo que el ingreso lo hacíamos solos lo digo en sentido literal. Teníamos mucho más acceso que estudiantes, abogados e incluso otros periodistas. Elegíamos el pabellón al cual queríamos ingresar, nos abrían la reja nos presentaban al grito "vienen de Cárceles" o "vienen de la tele" y volvían a cerrar la reja a nuestras espaldas. Los guardias volvían a sus actividades y nosotros nos quedábamos adentro de los pabellones. Solos con nuestras pertenencias. Lo cual es un dato llamativo también porque no nos revisaban, por ende entrábamos con nuestras mochilas. Llevábamos cigarrillos, tarjetas de teléfono, cuadernos para tomar notas. Pero también muchas veces llevábamos nuestros celulares y de haberlo querido cualquier otra cosa.

Hacer antropología, investigación social, e incluso investigación periodística, o producción de televisión en espacios como las cárceles conlleva enfrentarse a algunas cuestiones extra, específicas del espacio. La cárcel por sí misma, carga con un estigma y el investigador tiene que enfrentarse a él para poder penetrar su campo. No hay facilidades, por el contrario ingresar es complejo, arduo y las condiciones dentro del campo son a veces extenuantes. El encierro se siente en el cuerpo y en la mente. La seguridad, del otro, de la institución y la propia se ponen en juego. Si bien el investigador en general se encuentra en alerta cuando está en su campo, en general ese estado hace referencia a la captación de detalles y situaciones, a que nada se pase por alto. Cuando uno realiza trabajo de campo en una cárcel es estado de hipervigilacia 
excede a la investigación per se. Uno tiene que hacerse de los ruidos y los movimientos del lugar, aprehender los signos y síntomas, los movimientos, no solo para poder describirlos sino para saber moverse y prevenir situaciones de riesgo o incomodas, tanto con los detenidos como con los trabajadores del sistema penal. Cualquier movimiento fuera de lo acordado puede costarnos no volver a entrar. Este aspecto, sumado a las normas de un establecimiento penitenciario, que de por sí para acceder hay que pasar distintas guardias, desprenderse de objetos personales, pueden generarnos un agobio difícil de sortear.

Solíamos ir de a dos o tres, aunque incontables veces he ido sola. Cuando íbamos de a varios siempre nos pedían en la entrada que dejáramos el DNI y si alguno tenía celular. Uno de nosotros lo dejaba, pero los demás lo ingresábamos. Y los guardias lo sabían porque nos veían, pero todos hacíamos como si nada pasara. Entregábamos un teléfono e ingresábamos con el resto. Vale la pena aclarar que para el momento que realizábamos el programa los celulares eran mucho más modestos que ahora y ninguno de nosotros tenía un aparato como los de ahora (creo que ni existían), así que no podíamos ni grabar ni sacar fotos. Pero de alguna manera era nuestra una herramienta de seguridad. Si teníamos el teléfono teníamos un contacto con el exterior. $Y$ en la situación de encierro no es menor.

Los detenidos siempre nos pedían algo extra, pero creo que realmente no sabían con la libertad que ingresábamos. Y en eso nos amparábamos para responder los pedidos.

Manejar los pedidos es algo que uno tiene que aprender si tiene la intención de pasar una buena estadía si se puede decir en un penal. Cuando estás ahí vos "venís de afuera" todo lo que tenés "lo podés conseguir". En una primera instancia uno quiere hacer nuevos vínculos y cree que dándoles algo de lo que te están pidiendo te va a ayudar a ganar su simpatía. Sin embargo es de nunca acabar. "Vos le diste a ella tus aritos, dame a mi tu pulsera, prestame tu celular, traeme, comprame... más y más". Si bien uno no lleva muchas cosas de valor cuando va a un penal, en mi caso funcionó siempre responder lo mismo. "Los aritos me los regaló mi mamá, no te los puedo dar ni a vos ni a ninguna. Te traje cigarrillos, lo demás no me dejan pasar, no quiero tener problemas". Y como producción tratábamos de preguntar cuales eran las necesidades primordiales y tratábamos de aportar algo desde la caja chica de la productora. La realidad es que la productora no tenía un interés particular por satisfacer las necesidades de los detenidos, pero disponía una cierta cantidad de dinero para gastos de producción y nosotros como equipo tratábamos de administrarlo de manera tal de poder llevarles algo, ya sea ropa, yerba, cigarros, o cualquier otra cosa de uso común que estuvieran a nuestro alcance. En general eran cosas chicas. En algunos casos muy específicos hemos conseguido 
cosas puntuales que se necesitaban, como un termotanque, lavarropas. Pero si la productora se lo hubiese propuesto la ayuda podría haber sido mucho más significativa, desde los sponsor, canjes publicitarios. Pero en este caso no lo fue.

Los presos se encuentran en situación de privación de la libertad. Esto parece una obviedad, pero es por esta situación que en general reciben visitas, y es a través de su juzgado, su causa, su comportamiento que se evalúa su situación sus posibles beneficios o castigos. Cuando uno se acerca a hablar con un detenido en general el tema de la causa surge casi como carta de presentación, y en general aparece con otras cuestiones que lo rodean, culpabilidad, inocencia, justificación, pedidos al juzgado no cumplidos, quejas, y otras cuestiones. A su vez, cuando nos acercamos a un detenido el juzgado o el personal de la cárcel se interesan acerca de los motivos de ese acercamiento y tratan de sonsacarnos información. Es necesario no confundir nuestro rol. No somos jueces, no somos policías, no somos detectives, no somos víctimas ni victimarios. No ingresamos a la cárcel para juzgar o emitir una conclusión acerca del actuar "bueno o malo" de las personas que se encuentran allí y es necesario no creer que el lugar de investigador no nos da más poder que el entrevistado. Es más, muchas veces nuestra propia moralidad se pone en tela de juicio. Beatriz Kalinsky lo expone en relación no a las marcas de subjetividad presentes en cualquier campo, sino al hecho de confundirse o fusionarse con las razones de aquellos con quienes estamos interactuando

El proceso dialógico no exige despegarse, si quiera de modo circunstancial, de los modos de apoyo donde cada uno se sostiene. Entonces, esos eventuales desplazamientos subjetivos hacia quien está en una posición más débil por el monto de sufrimiento que acarrea y su cada vez más escasa posibilidad de superarlo puede llevar a una amplificación de la aceptación moral de ese "Otro" que no solo no es obligatoria sino que no siempre está fundamentada. (2011:25).

En estas situaciones, uno como investigador tiene que aprender a "mantener un equilibrio dinámico entre las propias convicciones y estos corrimientos que nos permiten acercarnos a estos sectores históricamente estigmatizados.

Por otra parte, en lo que respecta a la confidencialidad, si bien no hay una normativa vigente para los estudios antropológicos, a la hora de tomar decisiones acerca de determinado material 
debe triunfar la ética personal. No se busca hacer una investigación a toda costa, poniendo en riesgo a los entrevistados. Desde el mismo lineamiento se estipula un consentimiento informado, aunque esclarecer nuestro rol como investigador social a veces nos limite en nuestro acercamiento. En mi caso particular, algunas detenidas me conocían ya anteriormente por haber grabado con ellas. Todas las visitas de campo donde me acerque a ellas para hablar en el marco de esta tesis, se los aclaré antes de empezar la conversación. Creo que algunas veces no fue suficiente y la asociación de mi persona con el programa y el conductor (ambos que generaban amor y odio) en muchos casos me abrió y cerró puertas. Pero esto no fue motivo para dejar de hacerlo. Consideré importante para reforzar la construcción del vínculo con este "otro" que había elegido recalcar que si bien era la misma persona que ya habían visto dar vueltas por el penal con un equipo de televisión, en este caso estaba sola y con otros fines.

En mi trabajo de investigación procuré poner en juego mis subjetividades. No intenté aceptarlas per se, pero tampoco anularlas. Entiendo que tal como desarrolla Beatriz Kalinsky que "considerar la subjetividad como parte indeleble del conocimiento antropológico constituye una forma de ejercer responsablemente la profesión" (Kalinsky, 2011: 62) y que para acercarme a mis objetivos debía encontrar que la subjetividad tenga una presencia equilibrada en mi trabajo de campo, y no buscar o pretender una falta neutralidad valorativa. La riqueza de la investigación antropológica está en poder poner en juego la subjetividad de manera explícita para abordarla desde los beneficios y defectos.

Cuatro años después de la discontinuidad del ciclo, decidí retomar el tema de estudio, partiendo de mi experiencia de campo, de las notas recogidas en el mismo y el acceso al material fílmico utilizado en el programa "Cárceles", en el cual se emitieron las notas que yo misma he realizado como productora de televisión.

Retomé el tema de investigación en mis primeros meses de embarazo. Creo que mi estado en particular condiciona mi mirada sobre la maternidad y me obliga a reflexionar sobre cuestiones que antes desde la ignorancia no me había preguntado. Es mi primer embarazo y el desarrollo del mismo, así como el acceso a información antes desconocida por mí (como el curso de preparto, charlas sobre maternidad, etcétera) han expandido las fronteras de mi investigación, permitiéndome mirar desde otra perspectiva mis experiencias en el campo. Creo que el hecho de se haya dado un proceso paralelo entre escribir mi tesis de licenciatura y convertirme en madre fue muy enriquecedor, sobre todo porque pude identificar de que manera la maternidad cambiaba mi punto de vista sobre determinadas cuestiones y como me arrojaba claridad sobre otras. Reveer el material a través de mi propio proceso de construcción de mi maternidad me 
ayudó como herramienta para pensar la maternidad intra- muros. A su vez, he tenido que realizar un proceso de desnaturalización de mi propia experiencia para no contaminar la mirada de las madres detenidas sobre su propia maternidad, con mi experiencia personal.

Notas

(1) Los nombres de los funcionarios han sido cambiados para resguardar su identidad.

(2) En la televisión en general, en especial en los canales de aire, se busca que la imagen estética de las personas que salen en cámara sea agradable a la vista. Por muy subjetiva que pueda parecer esta apreciación, se busca que los entrevistados cumplan determinadas características como poseer todos los dientes. En programas como "Cárceles" o "Policías en Acción", no se hacía tanto hincapié en la apariencia física como en otros programas, sin embargo estaba presente la bajada de línea. Ambos programas se hicieron conocidos por romper con estos conceptos de la televisión clásica.

\section{Bibliografía}

Antony García, C. (2007). Mujeres invisibles: las cárceles femeninas en América Latina. Revista Nueva Sociedad, 208, marzo-abril.

Augé, M. (2014). El antropólogo y el mundo global. Buenos Aires: Siglo veintiuno.

Augé, M. y Colleyn, J. P. (2006). Qué es la antropología. Buenos Aires: Paidós.

Caimari, L. (2007). Entre la celda y el hogar. Dilemas estatales del castigo femenino (Buenos Aires, 1890-1940). Nueva Doctrina Penal, pp. 427-450. Recuperado de https://bit.ly/2IVTnUe 
Ciordia, C. y Villalta, C. (2015). Administrando soluciones posibles: medidas judiciales de protección de la niñez. Revista Latinoaméricana de Ciencias Sociales, Niñez y Juventud, 13(1). Recuperado de https://bit.ly/2kTb2vw

D’Antonio, D. (2011). Políticas de desarticulación de la subjetividad sexual y de género practicadas en la cárcel de Villa Devoto durante la última dictadura militar argentina (1976-1983). Revista Estudios, 25, enero-junio.

Da Cunha, M. I. P. (2004). El tiempo no cesa, La erosión de la frontera carcelaria. A renglón seguido, Renglones 58-59. Recuperado de http://ayp.unia.es/dmdocuments/umbrales06.pdf

Daroqui, A. (2002). La cárcel del presente, su "sentido" cómo práctica del secuestro institucional. En Gayol, S y Kessler, G. Violencias, delitos y justicias en la Argentina. Buenos Aires: Manantial. Universidad Nacional de General Sarmiento.

Felletti, K. (2011). Madre no hay una sola. Experiencias de maternidad en la Argentina. Buenos Aires: Ciccus.

Foucault, M. (2002). Vigilar y castigar. Nacimiento de la prisión. Buenos Aires: Siglo XXI.

Geertz, C. (2006). La interpretación de las culturas. Barcelona: Gedisa.

Goffman, E. (2008). Internados: Ensayos sobre la situación social de los enfermos mentales. Madrid: Amorrortu.

Graziano F.; Villalta C.; Ciordia C.; Gesteira S. y Fernández Tuñón, C. (2013). Confrontando sentidos sobre la maternidad 'no ideal': mujeres y madres presas en las cárceles de la provincia de Buenos Aires. VII Jornadas Santiago Wallace de Investigación en Antropología Social. Sección de Antropología Social, Instituto de Ciencias Antropológicas, Facultad de Filosofía y Letras, UBA, Buenos Aires.

Guber, R. (2014). La Etnografía. Método, campo y reflexividad. Buenos Aires: Siglo veintiuno.

Kalinsky, B. (2000). Justicia, cultura y derecho penal. Buenos Aires: Ad Hoc.

Kalinsky, B. (2006). "Ser mujer" en trabajos fronterizos: las marcas de género. Revista de Estudios de Género La ventana, 24, Universidad de Guadalajara Guadalajara, México, pp. 229-256. 
Kalinsky, B. (2006). Los usos de la prisión. La otra cara de la institucionalización. El caso de las mujeres encarceladas. Ley, Razón y Justicia. Revista de Investigaciones en Ciencias Jurídicas y Sociales, 7(10), pp. 181-204.

Kalinsky, B. (2008). El agente penitenciario: La cárcel como ámbito laboral. Runa, 28.

Kalinsky, B. (2011). Conocimiento Antropológico. Ética, subjetividad y condiciones del diálogo. Buenos Aires: Facultad de Filosofía y Letras.

Kalinsky, B. (2011). Hijos de la cárcel. Maternidad y encierro. En Felitti, K. (Comp.). Madre no hay una sola. Experiencias de maternidad en la Argentina (pp. 211-235). Buenos Aires: Ediciones Ciccus.

Kalinsky, B. y Cañete, O. (2010). Madres Frágiles. Un viaje al infanticidio. Buenos Aires: Biblos.

Kalinsky, B. y Cañete, O. (2005). La maternidad encarcelada. Un estudio de caso. Recuperado de https://bit.ly/2kp1QyD

Klein, M. (1990). Algunas conclusiones teóricas sobre la vida emocional del lactante (V. S. de Campo, S. Dubcovsky, V. Fischman, H. Friedenthal, A. Koremblit, D. Liberman, R. Malfé, N. Rosenblatt, N. Watson \& S. Zysman, Trads.). En Klein, M. Obras Completas, Tomo 3 (pp. 70-101). Buenos Aires: Paidós.

Klein, M. (1990). El desarrollo de un niño (H. Friedenthal y Aberastury, A. Trads.). En Klein, M. Obras Completas (Vol. 1, pp. 15-65). Buenos Aires: Paidós. (Trabajo original publicado en 1921).

Klein, M. (1990). Nuestro mundo adulto y sus raíces en la infancia. En Melanie Klein Obras Completas (Vol. 1, pp.). Buenos Aires: Paidós. (Trabajo original publicado en 1959).

Llobet, V. y Villalta, C. (2014). Resignificando la protección. Los sistemas de protección de derechos de niños y niñas en Argentina. Revista Latinoamericana de Ciencias Sociales, Niñez y Juventud, 13(1), pp 167-180.

Malinowski, B. (1926). Crimen y costumbre en la sociedad salvaje. Barcelona: Ediorial Ariel.

Malinowski, B. (1986). Los argonautas del pacífico. Barcelona: Planeta-De Agostini. 
Montalvo Cepeda, M. A. (2007). El ejercicio político de la maternidad en la cárcel de mujeres de Quito: testimonios y perspectivas. (Tesis de maestría). Estudios Sociales y Globales, Universidad Andina Simón Bolívar, Sede Ecuador.

Moreno, A. (2000) Los debates sobre la maternidad. En Fernández Montraveta, C.; Monreal Raquena, P.; Moreno, A. y Soto Rodríguez, P. (Comp.). Las representaciones de la maternidad (pp. 1-9). Madrid: Ediciones de la Universidad Autónoma de Madrid.

Ojeda, N. (2013). Cárcel de mujeres. Una mirada etnográfica sobre las relaciones afectivas en un establecimiento carcelario de mediana seguridad en Argentina. Sociedad $y$ economía, 25, pp. 237-254.

Ojeda, N. (2013). La cárcel y sus paradojas: los sentidos del encierro en una cárcel de mujeres. (Tesis doctoral). Buenos Aires, Unsam, IDAES.

Vacani, P. (2013). El tiempo de la pena y el tiempo en el encierro. Apuntes para el análisis del campo de prisión y la acción concreta en el campo judicial. En Zaffaroni, E. La medida cualitativa de prisión en el proceso de ejecución de la pena. Programa de Transferencia de Resultados de la Investigación-FD UBA. Recuperado de https://bit.ly/2klryi0 